\title{
CHILE EN 2012: LA CAMPAÑA PERMANENTE*
}

\section{Chile 2012: The permanent campaign}

\section{ROBERT L. FUNK}

Instituto de Asuntos Públicos, Universidad de Chile

\section{RESUMEN}

El tercer año del gobierno de Sebastián Piñera fue el primero en que tuvo la oportunidad de imponer su agenda. Superadas las crisis del terremoto de 2010 y de la irrupción de desencanto social de 2011, el gobierno de la Coalición por el Cambio pudo haber usado el año 2012 para dejar una huella en cuanto a la implementación de una agenda de políticas públicas. Sin embargo, la agenda política muy rápidamente se vio superada por un ambiente electoral, tanto por las elecciones municipales de octubre como por la aparición de candidatos testeando aguas para las presidenciales.

Palabras clave: Sebastián Piñera, política chilena, elecciones municipales, movilización social.

\begin{abstract}
Sebastian Piñera's third year in office was the first which offered the chance to implement a policy agenda. Having overcome the challenges of the 2010 earthquake and the appearance of social protest in 2011, the Coalition for Change government could have used 2012 to leave a real mark in terms of public policy. However, the public agenda very quickly became dominated by the electoral calendar, due to municipal elections in October and the appearance of candidates testing the waters for the presidential campaign.
\end{abstract}

Key words: Sebastián Piñera, Chilean Politics, Local Elections, Social Movement.

* Agradezco a Nicolás Miranda, Pablo Valenzuela y Alejandro Olivares por su inestimable colaboración y a evaluadores anónimos por los comentarios a las versiones preliminares del texto. Cualquier error u omisión, por supuesto, es de exclusiva responsabilidad del autor. 


\section{INTRODUCCIÓN}

La campaña presidencial de Sebastián Piñera se basó en una apuesta. Desde su programa presidencial hasta el logo de multicolores, Piñera enfatizó la continuidad. Ofrecía seguir con la economía social de mercado de la Concertación, con sus políticas sociales focalizadas, pero con un estado más moderno y eficiente. Sería una Nueva Forma de Gobernar. Pero también sería una nueva forma de ser gobierno para la derecha. Sebastián Piñera, apelando a su tradición de socialcristiano, trataba de representar de alguna forma a una derecha menos vinculada con la dictadura de Augusto Pinochet, más cercana al mundo empresarial, y dispuesto a bajarles el perfil a los temas valóricos, con el fin de construir una "nueva derecha".

El paper comienza con un resumen del contexto político durante el tercer año del gobierno de Piñera, examinando algunos de los eventos que marcaron 2012 para Chile. Se destacan en especial tres hitos principales: un clima electoral en torno a precandidaturas presidenciales, las elecciones municipales realizadas el 28 de octubre de 2012 y la continuación de la protesta social en una serie de temas, principalmente la educación. Se abordarán además las relaciones con los países vecinos, la economía, y algunas políticas o polémicas específicas como la muerte de Daniel Zamudio, Hidroaysén y la crisis de la educación superior.

La segunda sección, siguiendo en el plano político, resume el principal desafío en política exterior, que fue la fase oral del juicio en la Corte Internacional de Justicia de La Haya por la demanda marítima de Perú. Finalmente, se resume el año económico, resaltando los éxitos macroeconómicos, pero también algunos problemas que surgieron en esta materia.

\section{EL AÑO POLÍTICO}

De alguna forma el tercer año del gobierno de Sebastián Piñera fue el primero en que pudo funcionar con relativa 'normalidad'. La inauguración de su gobierno en 2010 estuvo -literalmente- marcada por el terremoto del 27 de febrero de ese año (la ceremonia de traspaso de mando fue interrumpida por una de las réplicas más fuertes de entonces). La segunda mitad de ese año se produjo el exitoso rescate de 33 mineros atrapados en la mina San José, lo que logró cambiar de tema y, momentáneamente, dar un salto a los niveles de popularidad del gobierno. El segundo año, sin embargo, estuvo dominado por las movilizaciones estudiantiles.

\section{Los presidenciables}

Si bien la principal contienda electoral de 2012 en Chile fueron las elecciones municipales, esto no impidió que las precandidaturas presidenciales se hicieran evidentes. El año fue dominado, por parte de la oposición, por la incertidumbre acerca de los planes de la expresidenta Michelle Bachelet, quien siguió liderando las encuestas de opinión pública, a pesar de no hablar con los medios sobre la contingencia del país. No obstante, ya en enero algunos candidatos comienzan a dejar en claro sus intenciones de participar en 
un proceso (sean estas primarias u otras), como, por ejemplo, el caso del ex-ministro de hacienda del gobierno de Bachelet, Andrés Velasco. ${ }^{1}$ En estricto rigor ya a mediados de 2011 Velasco comienza públicamente a hablar de una posible candidatura. ${ }^{2}$ En marzo, Claudio Orrego, alcalde democratacristiano de la comuna santiaguina de Peñalolén, anuncia que será precandidato. En julio el académico Franco Parisi anuncia también su candidatura independiente. ${ }^{3}$ Ximena Rincón, senadora del Partido Demócrata Cristiano, anunció a fines de 2011 su intención de postular. No fue mucha sorpresa que Marco Enríquez Ominami, quien desde la elección anterior se había dedicado a armar una base a lo largo del país, anunciara su candidatura, que lanza públicamente en octubre de 2012. ${ }^{4}$ Por su parte la izquierda extraparlamentaria tiene dos candidatos: Marcel Claude lanza su candidatura recién, el día 20 de enero de 2013, el Partido Igualdad proclamó como su candidata a la presidencia a Roxana Miranda.

Por parte del oficialismo, el entonces ministro de Defensa, Andrés Allamand, anuncia en julio, en una reunión de su partido, Renovación Nacional, que "se siente preparado" para asumir las responsabilidades presidenciales, pero recién en noviembre abandona su cargo ministerial para lanzar su candidatura. En enero de 2013 es proclamado como candidato de Renovación Nacional.

El caso de la UDI se destaca porque optó por apoyar la candidatura de Laurence Golborne, un ministro del gobierno de Piñera que no milita en ese partido. Sin embargo, como ministro de minería durante el rescate de los mineros de la mina San José, Golborne logró un nivel de popularidad que, si bien, no se sostuvo en el tiempo, continuó ubicándolo como uno de los políticos más populares del país. Se produce, entonces, una alianza entre un candidato con altos niveles de apoyo popular, pero sin partido, y un partido con un fuerte componente de base y organizacional, pero al que le faltaba un candidato. Es así que el 7 de noviembre de 2012, Golborne anuncia oficialmente su candidatura. ${ }^{5}$

El cargo que ejercía Michelle Bachelet en ONU Mujeres le impedía participar activamente en la política nacional, pero sus sostenidos altos niveles de apoyo en las encuestas de opinión pública mantuvieron la presión sobre la expresidenta (ver Gráfico 1). No fue hasta las vacaciones de fines de año, durante una visita al país, que Bachelet indicó que en marzo daría señales de su decisión respecto de una eventual candidatura. A mediados de marzo de 2013 Bachelet anunció que dejaría su cargo en la ONU, y el 27 del mismo mes lanzó oficialmente su candidatura. ${ }^{6}$

1 http://diario.elmercurio.com/detalle/index.asp?id=\%7Bb3da2b4f-22c0-417d-95d8-85a578592302\%7D (accedido el 17 de marzo de 2013).

2 http://www.latercera.com/noticia/politica/2011/07/674-382892-9-andres-velasco-sobre-una-posiblecandidatura-presidencial-el-tiempo-lo-dira.shtml (accedido el 17 de marzo de 2013).

3 http://www.emol.com/noticias/nacional/2012/07/08/549612/franco-parisi-lanzo-su-candidatura-presidencialcon-criticas-a-partidos-politicos.html(accedido el 17 de marzo de 2013).

4 http://www.latercera.com/noticia/politica/2012/10/674-486703-9-marco-enriquezominami-lanzo-oficialmentesu-candidatura-presidencial.shtml (accedido el 17 de marzo de 2013).

5 http://www.emol.com/noticias/nacional/2012/11/07/568373/golborne-quiero-ser-presidente-porqueconozco-la-realidad-de-cada-uno-de-los-chilenos.html (accedido el 17 de marzo de 2013).

6 http://www.latercera.com/noticia/politica/2013/03/674-515997-9-bachelet-confirma-repostulacion-a-lamoneda-he-tomado-la-decision-de-ser.shtml (accedido el 3 de abril de 2013). 
Grafico 1: ¿Quién le gustaría a Ud. que fuera la o el próximo presidente de Chile?

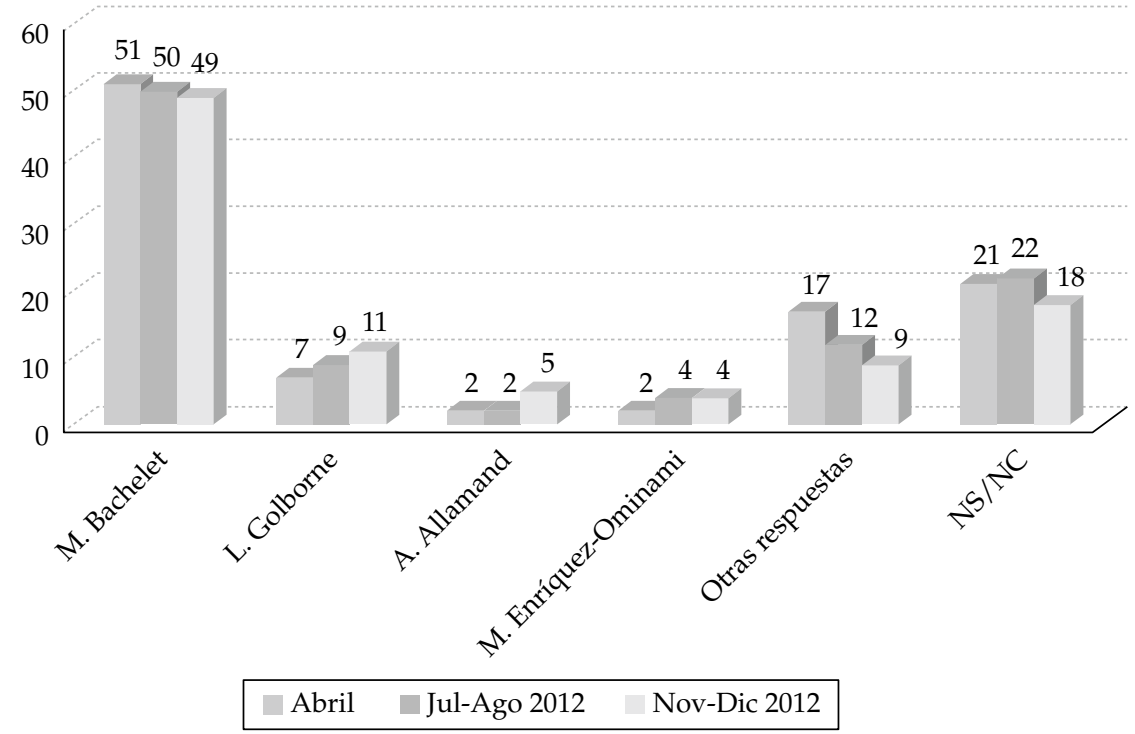

Fuente: CEP noviembre-diciembre 2012.

\section{Caso Zamudio/LAD}

El 27 de marzo fallece Daniel Zamudio, un joven de 24 años que había caído en coma después de haber sido agredido en el Parque San Borja, en Santiago, mientras regresaba a su hogar luego de una fiesta. El hecho causó consternación en la opinión pública por la naturaleza y nivel de violencia del ataque, que duró varias horas e incluyó que los atacantes marcaran el cuerpo de Zamudio con esvásticas y le cortaran una oreja.

El joven Zamudio permaneció 25 días en una clínica, período durante el cual diversos grupos solicitaron al gobierno que se avanzara en una Ley de Antidiscriminación que se encontraba estancada en el Congreso desde que fuera presentada por el ex-presidente Ricardo Lagos en 2005. Después de la muerte de Zamudio el gobierno le dio "suma urgencia" al proyecto de ley, que se aprobó en mayo.

La ley aprobada obliga al Estado a "elaborar e implementar las políticas destinadas a garantizar a toda persona, sin discriminación arbitraria, el goce y ejercicio de sus derechos y libertades", y define la discriminación arbitraria en función de la raza o etnia, la nacionalidad, la situación socioeconómica, el idioma, la ideología u opinión política, la religión o creencia, la sindicación o participación en organizaciones gremiales, sexo, orientación sexual, identidad de género, estado civil, edad, filiación, apariencia personal, enfermedad o discapacidad. ${ }^{7}$ Sin embargo, fue criticada por no crear una institucionalidad independiente que velara por la antidiscriminación, o que no se incluyera una sección 
que sancionara la incitación al odio. A la vez, se observó que la nueva ley solo contempló una multa, y no obligaba compensación alguna a las víctimas de discriminación.

\section{Elecciones municipales}

Las elecciones municipales del 28 de octubre de 2012 se producen en un contexto inédito. Por un lado, se realizan en un ambiente coyuntural bastante distinto a elecciones anteriores, con una combinación de movimientos sociales activos, un gobierno con bajos niveles de aprobación, una oposición desordenada, una economía sana, pero un malestar evidente. Sumado a lo anterior, se producen poco tiempo después de la implementación de un cambio que aumentó el padrón electoral gracias al nuevo sistema de inscripción automática y voto voluntario.

Las elecciones dejaron mucho para analizar. Por una parte, los resultados fueron inesperados, pues debido al cambio en el sistema de votación, en general las encuestas de opinión no pudieron ofrecer un panorama preciso, o incluso verosímil de lo que eventualmente ocurriría. Pocos esperaban que la coalición gobernante perdiera las alcaldías emblemáticas de Santiago y Providencia, además de municipalidades en el sector norte de la capital. La Concertación también ganó en Concepción. Pero más allá de lo emblemático, la Concertación superó al oficialismo en número de alcaldes y concejales elegidos, así como en el porcentaje de votos obtenido. Mirado desde el punto de vista de población gobernada, la Concertación también logró un gran avance, pasando de un $28 \%$ a un $49,5 \% .^{8}$

Este éxito concertacionista fue inesperado, en parte por el estado previo de la oposición, y porque las encuestas no indicaban tal resultado. La falta de precisión en las encuestas electorales fue una de las características destacadas de este proceso, debido en parte a la instauración de la inscripción automática y el voto voluntario. Más allá de eso, el éxito se explica por la política de alianzas de los partidos, los pactos entre el Partido Comunista y la Concertación, así como el apoyo a algunos independientes.

Otro elemento que llamó la atención, y que algunos analistas también atribuyeron al voto voluntario, fue el bajo nivel de participación, aunque la desprolijidad en la confección del padrón electoral dificulta la determinación de una tasa precisa de abstención. Según un estudio, la tasa de participación electoral (como porcentaje de adultos en edad de votar) bajó de un 58 a un 41\% (Observatorio Político-Electoral, 2012). En el proceso de actualización del padrón para efectos de inscripción automática, el Servicio Electoral registró a todos los chilenos vivos, incluso aquellos que residen fuera de Chile. ${ }^{9}$ Pero lo poco cuidadoso del proceso se vio extendido a otros aspectos del proceso electoral, de

8 http://www.latercera.com/noticia/opinion/ideas-y-debates/2012/10/895-490676-9-cinco-a-cero.shtml (accedido el 27 de febrero de 2013).

9 Un caso polémico fue la inclusión del fallecido presidente Salvador Allende, registrado en Estación Central. (http:/ / m.biobiochile.cl/notas/2012/10/28/salvador-allende-gossens-estaba-habilitado-para-votar-enestacion-central.shtml (accedido el 5 de abril de 2013). 
Gráfico 2: Alcaldes elegidos 2008-2012

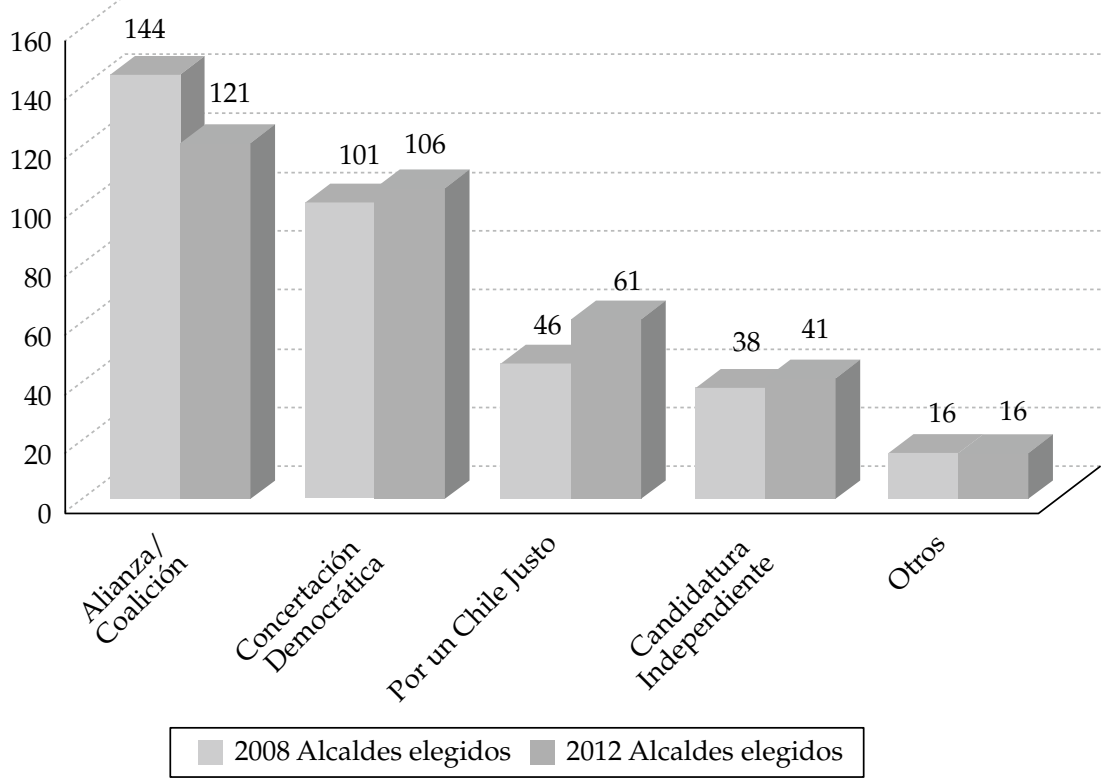

Fuente: Servel y elecciones.gov.cl

Gráfico 3: Elecciones de alcalde 2008-2012. \% votos

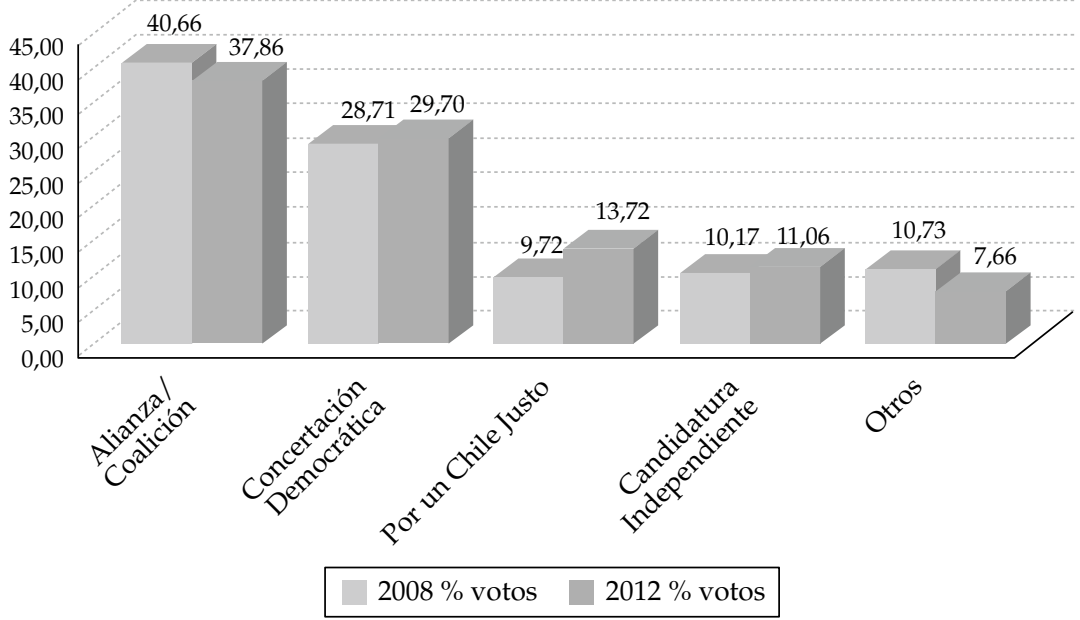

Fuente: Servel y elecciones.gov.cl 
manera que en algunas comunas emblemáticas, como Nuñoa, fue necesario hacer un reconteo supervisado por el TRICEL que cambió el resultado emanado el día de la elección.

Lo que efectivamente se pudo percatar fue que la inscripción automática y el voto voluntario confirmaron tendencias preexistentes en la política chilena, y tal vez las exacerbó. En las municipales de 2012 hubo una gran diferencia en participación electoral entre los quintiles más acomodados y los más pobres (Ver Tabla 1). También se percibió la alta tasa de abstención por parte de los más jóvenes, quienes son precisamente los que anteriormente no se habían registrado para votar. Ofrecida la oportunidad de votar sin tener que registrarse, los jóvenes -protagonistas de algunos de los principales movimientos sociales del último tiempo- optaron por no hacerlo.

Tabla 1: En la pasada elección municipal, ¿usted se abstuvo, es decir, no votó en la elección municipal, o usted sí votó en la elección municipal?

\begin{tabular}{lccccccccc}
\hline & \multicolumn{2}{c}{ Sexo } & \multicolumn{3}{c}{ Edad } & \multicolumn{3}{c}{ Nivel socioeconómico } \\
\cline { 2 - 9 } & Hombre & Mujer & $18-24$ & $25-34$ & $35-54$ & 55 y más & Alto & Medio & Bajo \\
\hline & $49 \%$ & $51 \%$ & $16 \%$ & $20 \%$ & $38 \%$ & $26 \%$ & $6 \%$ & $54 \%$ & $40 \%$ \\
Se abstuvo... & 41 & 44 & 60 & 58 & 34 & 31 & 17 & 39 & 51 \\
Sí votó & 58 & 54 & 40 & 41 & 63 & 67 & 83 & 59 & 48 \\
\hline
\end{tabular}

Fuente: CEP noviembre-diciembre 2012.

\section{Movilizaciones y educación}

El tema de educación, llevado a la atención pública por masivas manifestaciones durante 2011, continuó siendo uno de los principales focos de la política chilena durante 2012.

Las movilizaciones de 2011 demandaron regular el lucro que se sospechaba estaban obteniendo las universidades privadas, pero que por ley está prohibido. A la vez, los estudiantes llamaron la atención sobre la mala calidad de la educación pública, particularmente en los liceos municipales, y las tasas de interés de los créditos con aval del Estado. Los tres puntos esenciales tenían en común una crítica a la forma en que se había construido la institucionalidad educacional en Chile durante los últimos treinta años, por lo que las demandas se basaban en un llamado por refundar el sistema educacional, alejándolo de un modelo neoliberal y exigiendo un aumento en la asignación de recursos públicos para el mismo. Esto se tradujo, además, en una demanda por reformas políticas y económicas, como la renacionalización del cobre y una profunda reforma tributaria, sin las cuales se consideraba que sería imposible avanzar con reformas sustantivas en la educación.

A lo largo de 2011 los movimientos sociales organizaron marchas, algunas de las cuales reunieron más de cien mil personas, pero también otras formas de manifestación donde destacaba la "creatividad" de los estudiantes (una corrida por la educación alrededor del Palacio de la Moneda, una besatón, o un masivo "flash mob" bailado al ritmo del 
clásico Thriller de Michael Jackson) logró atraer la atención de la opinión pública a la causa, tanto a nivel nacional como desde la prensa extranjera. ${ }^{10}$

Durante 2012 se vivió una continuación del malestar ciudadano, expresada en diversas campañas de movilización social. El movimiento estudiantil continuó, si bien con menos fuerza que el año anterior, víctima de una estrategia de desgaste por parte del gobierno y de un cambio en las cúpulas de liderazgo, un tanto menos inspiradoras que sus antecesores.

En abril el Ministro de Educación señaló que se reformularía el sistema de financiamiento de la educación superior, unificando los dos sistemas de crédito universitario existentes, Fondo Solidario y Crédito con Aval del Estado, de manera que la banca privada quedara fuera del sistema de financiamiento. ${ }^{11} \mathrm{El} 25$ de abril se realiza la primera marcha importante del año que albergó a unas 48 mil personas según Carabineros y 80 mil según la Confech. ${ }^{12}$

En mayo, previo a la cuenta anual del 21 de mayo, se realiza otra manifestación con la participación de entre 50 mil y 100 mil personas.

El 24 de junio la Comisión Investigadora sobre el Funcionamiento de la Educación Superior dio a conocer la totalidad del informe que acusó distintas maniobras utilizadas ${ }^{13}$ por siete universidades y un instituto profesional para violar la ley que les impide repartir utilidades. ${ }^{14}$ Cuatro días más tarde, alrededor de 120 mil personas salieron a la calle a protestar. ${ }^{15}$ En agosto, una marcha autorizada procedió por la vía principal de Santiago, la Alameda, terminando con enfrentamientos entre carabineros y manifestantes y con tres buses quemados. ${ }^{16}$ Otras marchas en agosto llegaron a tener hasta 130 mil-150 mil personas participando en Santiago. ${ }^{17}$

Después de agosto las manifestaciones comienzan a perder fuerza. Carabineros estimó que una marcha el 11 de octubre, organizada para rechazar el proyecto de Presupuesto 2013 en educación, no superó los cinco mil participantes. ${ }^{18}$

Aparte de las manifestaciones por la calidad de la educación se produjeron movimientos sociales en otros ámbitos. Durante febrero -tradicionalmente un mes tranquilo por ser

10 http://ca2011.13.cl/nacional/mas-de-100-mil-personas-participaron-en-historica-marcha-estudiantil-ensantiago(accedido el 5 de abril de 2013).

11 http://diario.latercera.com/2012/04/24/01/contenido/pais/31-106967-9-mineduc-propone-creditouniversitario--estatal-que-elimina-a-la-banca-privada.shtml (accedido el 3 de abril de 2013).

12 http://www.lasegunda.com/Noticias/Educacion/2012/04/740848/A-las-1100-horas-comienza-primeramarcha-estudiantil-del-ano-en-Santiago (accedido el 3 de abril de 2013).

13 http:/ / www.cooperativa.cl/las-siete-formas-legales-que-pueden-usar-las-universidades-para-lucrar / prontus_nots/2012-06-15/183554.html (accedido el 3 de abril de 2013).

14 http://www.cooperativa.cl/prontus_nots/site/artic/20120624/pags/20120624130026.html(accedido el 3 de abril de 2013).

15 http://www.cooperativa.cl/el-minuto-a-minuto-de-la-marcha-estudiantil-de-este-jueves/prontus_nots/201206-28/095534.html (accedido el 3 de abril de 2013).

16 http://www.biobiochile.cl/2012/08/08/estudiantes-secundarios-realizan-marcha-no-autorizada-por-lascalles-de-santiago.shtml (accedido el 3 de abril de 2013).

17 http://diario.latercera.com/2012/06/29/01/contenido/pais/31-112694-9-alta-convocatoria-y-desmanes-ennueva-marcha-estudiantil-por-la-alameda.shtml (accedido el 3 de abril de 2013).

18 http://noticias.terra.cl/nacional/politica/marcha-estudiantil-por-presupuesto-de-2013-termina-en-santiagocon-disturbios,5756134c6274a310VgnCLD2000000ec6eb0aRCRD.html (accedido el 3 de abril de 2013). 
de vacaciones- se formó un movimiento social en la región de Aysén, una zona austral en la que, por su distancia del centro del país, la vida es especialmente costosa. Los residentes de Aysén exigieron a las autoridades un petitorio "histórico", encabezado por un subsidio a los combustibles y mejoras en los servicios que entrega el Estado (particularmente en las áreas de salud y educación). Se realizó un llamado para que se instalara una universidad pública, por un salario mínimo regionalizado y una mejora en las pensiones; la regionalización de los recursos naturales y la generación de mecanismos vinculantes en la decisión de los proyectos de construcción de represas. ${ }^{19}$ Se exigieron, además, medidas de protección a favor de la pesca artesanal, una de las fuentes de ingreso principales de la zona (CLACSO, 2012a).

Durante varias jornadas hubo duros enfrentamientos con carabineros, lo que llevó a que desde el gobierno central se enviara una gran cantidad de contingente policial. El 15 de marzo, tras un intenso choque entre ciudadanos y fuerzas especiales de la policía, un bus de carabineros es quemado por los manifestantes, razón por la cual el gobierno decidió aplicar la Ley 12.927 de Seguridad del Estado contra 22 personas (CLACSO, 2012b).

A finales de marzo, tras varios intentos de negociación infructuosos, representantes del movimiento social de Aysén asistieron al Palacio de la Moneda y lograron un acuerdo con el gobierno en varios de los puntos del petitorio, así como que el gobierno desistiera en la aplicación de la Ley de Seguridad del Estado. Entre los puntos principales de este acuerdo están el de nombrar a Aysén como zona franca de región aislada, un subsidio a la leña, una bonificación a la mano de obra cancelada directamente a cada trabajador, mejoras en los servicios básicos, entre otros. ${ }^{20}$ Una consecuencia no esperada del conflicto fue que el 27 de marzo renuncia el Ministro de Energía, Rodrigo Álvarez, por sentirse excluido del proceso final de negociación, a pesar de haber sido un rostro visible del oficialismo en las negociaciones anteriores. ${ }^{21}$

Otro conflicto importante se dio en la comuna de Freirina, donde un grupo de pobladores se manifestó en contra de los malos olores que provocaba la planta procesadora de cerdos de la empresa "Agrosuper", así como la extracción de agua proveniente de napas subterráneas, lo que está prohibido por la Dirección General de Aguas. La comunidad se movilizó para exigir que la autoridad investigara y prohibiera el funcionamiento de la planta. ${ }^{22}$ Este conflicto aumentó su tensión, llegando a involucrar a tres comunas de la región de Atacama -Huasco, Vallenar y Freirina-, las cuales realizaron varias manifestaciones, incluyendo cortes de la ruta entre Freirina y Huasco, lo que desembocó en un enfrentamiento con carabineros.

Polémica y también protesta por parte de pescadores artesanales causó la discusión y eventual aprobación de la Ley de Pesca, que cambió la antigua forma de distribuir

19 http://www.cooperativa.cl/conozca-el-petitorio-del-movimiento-social-de-aysen/prontus_nots / 2012-0216/152619.html(accedido el 6 de abril de 2013).

20 http:/ /www.latercera.com/noticia/politica/2012/03/674-439647-9-gobierno-anuncia-acuerdo-con-dirigentesde-aysen-tras-jornada-de-trabajo-en.shtml (accedido el 6 de abril de 2013).

21 http://www.latercera.com/noticia/politica/2012/03/674-440282-9-ex-ministro-alvarez-explica-su-renunciay-critica-al-gobierno-soy-el-rostro-de.shtml (accedido el 6 de abril de 2013).

22 http://radio.uchile.cl/noticias/150076/ (accedido el 3 de abril de 2013). 
derechos a las aguas y las cuotas de reserva. ${ }^{23}$ La oposición criticó la ley aduciendo que la nueva normativa entregaba derechos transferibles a empresas en base a su participación histórica en la industria, asegurando así la continuidad de la concentración económica en este sector. ${ }^{24} \mathrm{El}$ principal movimiento que se organizó en oposición a esta ley llegó a hablar de que la industria sería controlada por siete familias. ${ }^{25}$ En enero de 2013 el Tribunal Constitucional rechazó las impugnaciones que habían presentado parlamentarios de la oposición, basándose en que favorecía de manera arbitraria a algunos empresarios y que no se había consultado a las comunidades indígenas afectadas. ${ }^{26}$

\section{CONTEXTO INTERNACIONAL}

\section{La Haya}

En diciembre se inicia la fase oral del juicio en la Corte Internacional de Justicia en La Haya, donde Perú presentó una demanda contra Chile para fijar la frontera marítima entre los dos países.

La posición del gobierno, durante las semanas previas y el desarrollo de la fase oral del juicio, tuvo dos características centrales. La primera fue resaltar el carácter nacional del asunto. A través de sus declaraciones y reuniones con los expresidentes, se optó por un mensaje de unidad nacional y de política de Estado. El Presidente de la República declaró que "esta no es la causa de un gobierno, es la causa de todo Chile. Queremos que todos los Presidentes estén perfectamente informados y sobre todo absolutamente comprometidos con la defensa de la causa chilena (...) Chile está totalmente unido en defender nuestros mares, nuestros territorios, nuestras soberanías". ${ }^{27}$

El lunes 3 de diciembre de 2012 se inicia la fase oral con la presentación de Perú. Chile presentó sus argumentos el jueves 6 y el viernes 7 de diciembre. Una reunión entre el equipo chileno y el jefe de la delegación, Alberto van Klaveren, se realizó el mismo lunes 3 de diciembre por la mañana. El jefe de la delegación de Perú fue el ex canciller Allan Wagner, que se encontraba en Holanda semanas antes del inicio de los alegatos.

La segunda característica de la posición del gobierno fue enfatizar el carácter jurídico del juicio, relevando la situación de los acuerdos y tratados internacionales y dejando de lado dimensiones políticas del mismo. El argumento principal del gobierno se basó en la existencia de tratados internacionales que fijaban los límites marítimos, situación que Perú negaba aludiendo que solo existen acuerdos pesqueros. Asimismo, Chile buscó sustentar su argumentación en el cumplimiento de los tratados y el ejercicio de

23 http://radio.uchile.cl/noticias/161120/ (accedido el 3 de abril de 2013).

24 http://www.latercera.com/noticia/nacional/2012/07/680-471587-9-las-cinco-claves-de-la-ley-de-pesca-quegenera-protestas-en-las-ciudades.shtml (accedido el 3 de abril de 2013).

25 http://radio.uchile.cl/noticias/178853/(accedido el 3 de abril de 2013).

26 http://www.latercera.com/noticia/negocios/2013/01/655-505409-9-tribunal-constitucional-rechazaimpugnacion-a-la-ley-de-pesca.shtml (accedido el 3 de abril de 2013).

27 http://www.latercera.com/noticia/politica/2012/11/674-495224-9-presidente-pinera-y-cita-con-ex-mandatariospor-la-haya-esta-no-es-una-causa-de.shtml (accedido el 4 de abril de 2013). 
la soberanía. Para ello, durante el mismo juicio se presentaron una serie de documentos y textos reconocidos por el gobierno peruano que sí mostraban el límite marítimo en el paralelo, avalando la postura chilena.

En este punto, el gobierno recibió el respaldo cerrado de todas las fuerzas políticas del país expresadas tanto en los presidentes de las comisiones de relaciones exteriores de la cámara de diputados y del senado y en los partidos políticos ${ }^{28}$.

Paralelo a la demanda limítrofe con Perú, las relaciones con Bolivia también sufrieron un deterioro, luego de que en marzo de 2011 el gobierno de Bolivia anunciara que iniciaría el proceso para demandar a Chile en la Corte Internacional de Justicia. ${ }^{29}$ Este hecho es parte de un deterioro progresivo de las relaciones entre Chile y Bolivia, lo que ha tenido un impacto tanto en la política doméstica boliviana, como en los foros multilaterales de la región y el hemisferio, incluyendo la OEA y Naciones Unidas. Las tensiones llevaron al presidente boliviano, Evo Morales, a señalar que Chile "es un peligro para la región". ${ }^{30}$ La actitud de Bolivia es probablemente explicada debido al plazo de cuatro años que la propia Constitución le pone al gobierno de Evo Morales para resolver el tema marítimo.

Otro hito que marcó la política exterior durante 2012 fue la constitución formal de la Alianza del Pacífico en junio, durante una cumbre realizada en el Cerro Paranal. La Alianza del Pacífico ha sido situada como una herramienta de inserción económica contraria (o bien, complementaria) al Mercosur, que apuesta por la liberalización económica y la apertura comercial. Los miembros de la Alianza -Chile, Colombia, Perú y Méxicotienen tratados de libre comercio entre sí y buscan formar parte de la alianza más amplia propuesta por los Estados Unidos, el Trans Pacific Partnership (TPP). ${ }^{31}$

\section{EL AÑO ECONÓMICO}

En el aspecto económico, el gobierno de Sebastián Piñera llegó al poder prometiendo una tasa de crecimiento de un $6 \%$ promedio y la creación de un millón de nuevos empleos (Piñera, 2009).

En 2010, Piñera recibió una economía que comenzaba a recuperarse del ciclo recesivo causado por la crisis financiera internacional. Esto significó, sin embargo, que el punto de partida fuera inusualmente bajo (en 2009 la economía experimentó una contracción de 1,7\%), y también que el país estaba recién comenzando a percibir los beneficios del

28

http:/ /www.latercera.com/noticia/politica/2012/07/674-470710-9-tarud-tras-reunion-con-pinera-por-demandaperuana-tenemos-que-poner-todos-los.shtml; http://www.latercera.com/noticia/politica/2012/10/674489008-9-presidente-pinera-se-reune-con-los-lideres-de-todos-los-partidos-politicos-para.shtml (accedido el 6 de abril de 2013).

29 http://www.latercera.com/noticia/politica/2011/12/674-412161-9-evo-morales-anuncia-viaje-a-la-haya-parapreparar-demanda-maritima-contra-chile.shtmlhttp://www.latercera.com/noticia/politica/2011/11/674407431-9-bolivia-reafirma-intencion-de-llevar-ante-la-haya-demanda-maritima-en-contra-de.shtml (accedido el 9 de abril de 2013).

30 http://www.latercera.com/noticia/mundo/2012/10/678-486115-9-evo-morales-afirma-que-chile-es-unpeligro-para-la-region.shtml (accedido el 9 de abril de 2013).

31 (http://www.gob.cl/destacados/2012/06/06/presidente-pinera-inauguro-iv-cumbre-de-la-alianza-delpacifico-en-paranal-junto-a-mandatarios-de-me.htm (accedido el 9 de abril de 2013). 
plan de estímulo implementado por el entonces ministro de Hacienda del gobierno de Bachelet, Andrés Velasco. Dicho plan, anunciado en enero de 2009, implicó un gasto de cuatro mil millones de dólares, representando casi un 3\% del Producto Interno Bruto. El fondo fue invertido en proyectos de infraestructura, subsidios y en la capitalización de CODELCO, entre otros. ${ }^{32}$ Este estímulo, más el gasto público y privado que requeriría la reconstrucción después del terremoto del 27 de febrero. Esto dejó las bases para una fuerte demanda interna que han llevado a las tasas de crecimiento de 5,6\% en 2012. ${ }^{33}$

Dicha tasa estaba dentro de lo esperado, dado que los organismos internacionales habían notado el buen momento económico del país después de la crisis de 2009. El Fondo Monetario Internacional, por ejemplo, rectificó en octubre las cifras proyectadas para Chile en 2012, aumentando el crecimiento proyectado de un 4,3\% -señalado en abrila un $5 \%$, y reduciendo la proyección de inflación prevista de un 3,8\% a un 3,1\%. ${ }^{34}$ Por su parte, la OCDE señaló en noviembre que Chile, a pesar de los efectos de la crisis económica, sería la nación con mayor crecimiento dentro de este grupo de países con un $5,2 \%$, y lo seguiría siendo en los próximos años.

\section{Gráfico 4: PIB Variación anual}

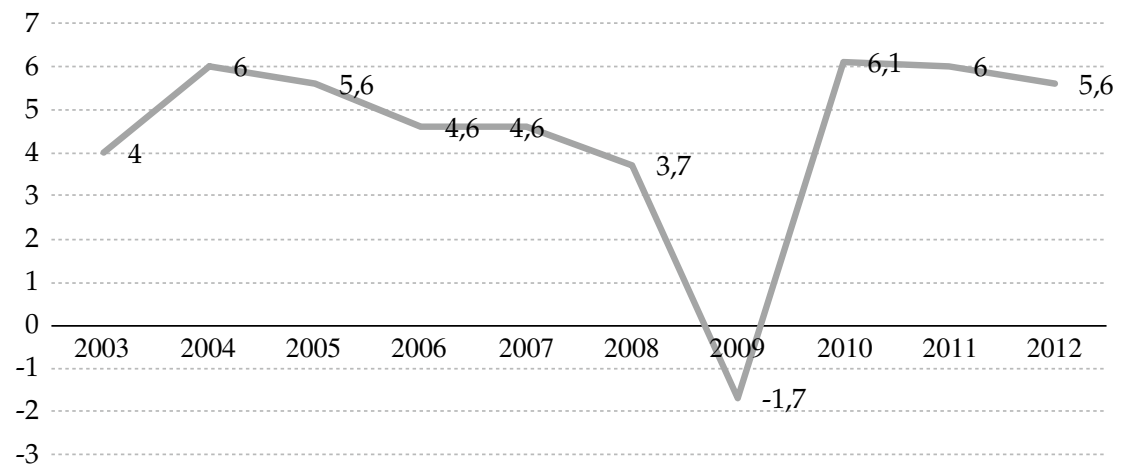

Fuente: Banco Mundial.

Asimismo, el manejo fiscal por parte del gobierno de Sebastián Piñera ha recibido observaciones ambivalentes. Por un lado, a diciembre de 2012 el gobierno central mantiene un déficit estructural del 1\% del PIB con un superávit efectivo de 0,6\% del PIB. ${ }^{35}$ En 2012, al mismo tiempo, los ingresos del gobierno central crecieron un 1,3\% respecto del

el 26 de marzo de 2013).

33 http://www.emol.com/noticias/economia/2013/03/18/588934/banco-central-confirmo-que-la-economiachilena-crecio-56-en-2012.html (accedido el 16 de marzo de 2013).

34 http://www.latercera.com/noticia/negocios/2012/10/655-487301-9-fmi-eleva-proyeccion-de-crecimientopara-chile-en-2012-a-5-desde-43.shtml

35 La diferencia en este punto ocurre porque el superávit está siendo alimentado por ingresos transitorios del fisco. El déficit estructural implica que hay gastos permanentes que no tienen un correlato en ingresos permanentes. 
año anterior, mientras que los gastos aumentaron un 4,7\%. El precio del cobre alcanzó un promedio de 360 centavos de dólar, completando para los tres primeros años de gobierno un promedio de 367 centavos de dólar. Superior a los 294 centavos por libra que alcanzó en promedio durante los cuatro años del gobierno de Bachelet.

Lo anterior va acompañado de un amplio dinamismo interno que ha sostenido un crecimiento económico en torno al $6 \%$. Sin embargo, dadas estas ventajosas condiciones el gobierno no ha podido alcanzar un balance estructural de las cuentas fiscales, lo que ha llevado a que el gobierno reciba críticas por el expansivo manejo fiscal ${ }^{36}$ y por el alto déficit de cuenta corriente que mantiene el país, en torno al 3\% del PIB en 2012, lo cual puede llegar a ser un riesgo subyacente para la economía que reduce el espacio de maniobra que tiene la autoridad monetaria para tomar medidas. ${ }^{37}$ Frente a esto, el Ministro de Hacienda Felipe Larraín ha señalado que el gobierno ha sido moderado en el gasto público, expandiéndolo a un ritmo menor que el crecimiento de la economía (4,8\% vs $5,9 \%$ promedio) para recuperar el equilibrio fiscal, ${ }^{38}$ destacando además la sostenibilidad del déficit que mantiene el gobierno.

Además, Chile ha realizado colocaciones de dos bonos en el extranjero durante el año, los que recibieron las mejores condiciones históricas de financiamiento para Chile y para cualquier país latinoamericano o emergente. En esa misma línea, en diciembre de 2012, la calificadora Standard \& Poor's pasó la evaluación chilena de A+ a AA-. ${ }^{39}$

\section{Reforma tributaria}

Uno de los hitos más importantes del año fue la negociación de una reforma tributaria, anunciada por el Presidente de la República el 11 de diciembre de 2011 como respuesta a un creciente debate que se venía dando respecto del sistema impositivo en el país y como respuesta a demandas en el ámbito de la educación. La reforma se planteó para alcanzar una recaudación adicional de 1.257 millones de dólares, los que según el gobierno serían destinados íntegramente a la educación.

Luego de casi cuatro meses de discusiones por la prensa, durante los cuales el gobierno fue entregando los detalles de la propuesta a cuentagotas, el proyecto de ley fue ingresado al congreso el 3 de mayo de 2012 para su discusión. La Concertación abogó por una reforma profunda y en la medida en que el gobierno revelaba detalles del proyecto las críticas de la oposición fueron creciendo, señalando que era solo un cambio cosmético y que debía ser discutida en profundidad con los actores políticos y sociales. En medio de estas discusiones el presidente defendía el proyecto y llamaba a que fuera rápidamente

36 http://www.df.cl/la-administracion-pinera-larrain-perforo-la-politica-fiscal-gastando-mas-de-lo-que-serecauda/prontus_df/2013-01-27/205936.htmlhttp://m.df.cl/senadores-piden-reforma-tributaria-pararecuperar-balance-estructural-del-pais/prontus_df/2012-03-26/114114.html (accedido el 10 de abril de 2013).

37 http://www.elmostradormercados.cl/blogs/el-deficit-de-cuenta-corriente-y-la-necesidad-del-ahorro-fiscal/ (accedido 10 de abril de 2013).

38 http:/ / www.economiaynegocios.cl/noticias/noticias.asp?id=106815 (accedido el 10 de abril de 2013).

39 http://www.emol.com/noticias/economia/2012/12/26/576420/standard--poors--eleva-calificacion-soberanade-chile-en-un-escalon-a-aa-.html (accedido el 10 de abril de 2013). 
aprobada en el Congreso incluso antes que el proyecto se elaborara completamente e iniciará su discusión legislativa.

En líneas generales el proyecto contemplaba el fin de exenciones injustificadas y vacíos legales que facilitaban la elusión, así como nuevas facultades de fiscalización en materia de precios de transferencia; y por un nuevo tratado tributario simétrico entre sociedades anónimas y sociedades de personas. Se propuso la mantención de la tasa de impuesto de primera categoría en $20 \%$, la que originalmente era transitoria para financiar la reconstrucción posterior al terremoto. Se reducían además los impuestos personales de segunda categoría y se creaba crédito tributario imputable a los gastos de educación. En términos de bajas, se reducía el impuesto de timbres y estampillas y se eliminaban aranceles aduaneros, entre otras medidas.

Las primeras discusiones relativas a los efectos de la reforma giraron en torno al monto adicional que se recaudaría por efectos de las nuevas cargas impositivas. Una de las mayores críticas se fijó en que los cambios propuestos podrían terminar favoreciendo a sectores económicos no necesitados. Segundo, se criticó que en el balance de las alzas y rebajas de impuesto, lo recaudado no sería suficiente para enfrentar los desafíos en educación ni en otras áreas sociales.

En esa misma línea, la reforma recibió críticas por dos frentes. Algunos partidarios del gobierno, por ejemplo, el senador de la UDI Jovino Novoa observó la falta de una rebaja o eliminación del impuesto a los combustibles; y, por parte de la oposición, hubo dos nudos fundamentales: la rebaja impositiva de los tramos medios y al alza de los tramos más altos de ingresos, y también la utilización del crédito a gastos educacionales.

El acuerdo se alcanzó cuando el gobierno atenuó la rebaja impositiva en los tramos de ingresos mayores a 2,7 millones, y realizado una rebaja mayor en los tramos inferiores a los dos millones. Respecto del crédito a los gastos en educación, el ejecutivo accedió a ampliar el beneficio para gastos en colegios municipales con un gasto presunto de 100 mil pesos. ${ }^{40}$

\section{Medición de pobreza}

Una controversia surgió en 2012 cuando la Comisión Económica para América Latina y el Caribe (CEPAL) anunció que dejaría de participar en la elaboración de la encuesta CASEN, que mide la pobreza en Chile. Esta decisión, de parte de una de las tres organizaciones a cargo de la encuesta (las otras dos son el Centro de Microdatos de la Universidad de Chile y el Instituto Nacional de Estadísticas), se tomó luego de que la CEPAL informara al gobierno una tasa de pobreza de 15\%, lo que implicaba que no se había reducido la pobreza desde la última medición realizada en 2009, que reportó una tasa de pobreza de 15,1\%. Unos días más tarde, funcionarios del Ministerio de Desarrollo

40 http://diario.latercera.com/2012/09/04/01/contenido/pais/31-117583-9-gobierno-logra-sellar-acuerdocon-la-oposicion-para-aprobar-reforma-tributaria.shtml (accedido el 4 de abril de 2013). 
Social le solicitaron a la CEPAL que se incluyera una pregunta adicional en el cálculo, lo que implicaría una reducción de la pobreza de casi un punto porcentual. ${ }^{41}$

La controversia respecto de si hubo o no interferencia política en la elaboración de la Encuesta CASEN de 2012 llevó a destacados académicos a expresar preocupación por cómo el gobierno estaba manteniendo sus estadísticas. ${ }^{42} \mathrm{El}$ gobierno anunció que suspendería la encuesta de 2012, y buscaría otras fórmulas para, según el presidente Piñera, "ampliar y perfeccionar" el concepto de la pobreza. ${ }^{43}$

\section{CONCLUSIÓN}

Tras el rescate de los mineros, el presidente Sebastián Piñera alcanzó su peak en aprobación, llegando a un 63\%, lo que significó un aumento de 10 puntos porcentuales en comparación a la medición anterior. ${ }^{44}$ Durante los seis meses siguientes la aprobación del presidente bajó constantemente hasta encontrar un punto de equilibrio entre los 30 y 40 puntos. ${ }^{45}$ La baja popularidad del presidente y su gobierno ha sido una constante durante 2011 y 2012, y tomado en perspectiva comparada representa un período extendido de baja popularidad muy por debajo de lo observado en gobiernos anteriores (ver Gráfico 5). Adicionalmente, tomando en cuenta los buenos resultados económicos, representa una especie de paradoja.

Resumiendo el 2012, sin embargo, es posible identificar algunas claves que podrían ayudar a descifrar este misterio. Primero, tanto durante 2011 como en 2012 el gobierno de Piñera fue el objeto de diversos tipos de protesta social, de un tipo e intensidad que no se había visto en Chile desde el retorno de la democracia. Mientras es verdad que estas protestas eran sintomáticas de profundos problemas y un desencanto real, también es probable que hayan contribuido a crear una sensación de, en el mejor de los casos, mal manejo de conflicto político, y en el peor de los casos, de crisis.

Un segundo elemento que se hace evidente en este resumen es que, habiendo tenido que dedicar los primeros dos años al manejo de crisis imprevistos, se acabó el tiempo de Piñera. Los gobiernos de cuatro años sufren prematuramente del síndrome del pato cojo, y la irrupción de precandidaturas presidenciales, tanto por parte de la oposición como dentro del oficialismo, lo cual implica que el período real de un gobierno chileno bajo el sistema actual -es decir, la ventana que tiene para implementar grandes cambios o dejar una impronta significativa- es de dos años.

41 http:/ / ciperchile.cl/2012/08/31/las-desconocidas-gestiones-del-gobierno-ante-la-cepal-que-lograron-bajarlos-indices-de-pobreza/ (accedido el 9 de abril de 2013).

42 http://ciperchile.cl/2012/09/14/expertos-de-la-cepal-y-del-cep-exigen-a-mideplan-que-divulgue-pretestde-encuesta-casen-2011/ (accedido el 9 de abril de 2013).

43 http://www.latercera.com/noticia/negocios/2012/10/655-489271-9-gobierno-suspende-casen-2012-y-elevaestandares-para-medir-la-pobreza.shtml (accedido el 9 de abril de 2013).

44 http://www.cooperativa.cl/adimark-rescate-de-mineros-llevo-aprobacion-de-pinera-a-su-nivel-mas-alto/ prontus_nots/2010-11-02/100153.html (accedido el 27 de marzo de 2013) http:/ / www.latercera.com/noticia/ politica/2010/11/674-304176-9-adimark-pinera-sube-10-puntos-en-aprobacion-tras-rescate-de-mineros.shtml (accedido el 27 de marzo de 2013).

45 Ver encuestas Adimark de octubre de 2010 en adelante. Adimark.cl 
Gráfico 5: Evolución de evaluación de los gobiernos. Chile 2000-2012

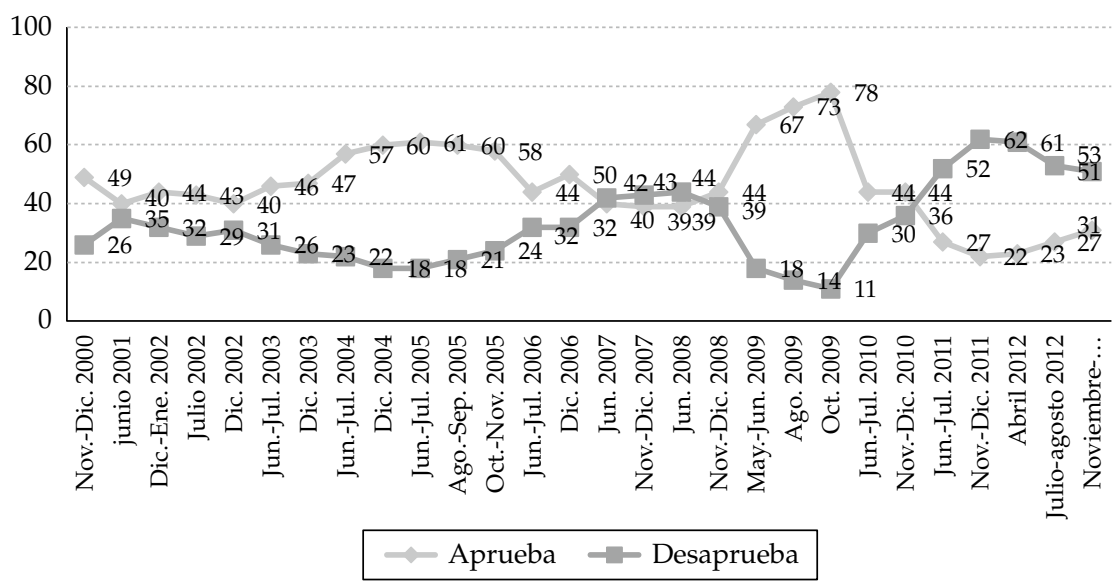

Fuente: CEP noviembre-diciembre 2012.

Esta situación se vio exacerbada por las elecciones municipales, durante las cuales la energía política estuvo dedicada a campañas en el nivel local. Una vez concluidas estas elecciones, durante bastante tiempo la narrativa estuvo concentrada en dos aspectos: los inesperados buenos resultados por parte de la Concertación, y el mal manejo del proceso electoral por parte de las autoridades. Mientras es razonable suponer que la realización de un proceso electoral bajo nuevas reglas pueda traer problemas, la desprolijidad afectó con especial intensidad a un gobierno que había hecho campaña prometiendo buena gestión. El manejo de los procedimientos electorales, o la polémica por la Encuesta CASEN, llevaron a algunos observadores a concluir que existía, en el mejor de los casos, cierto nivel de improvisación, o en el peor, la sospecha de una "ingeniería" institucional para el beneficio político.

A la vez, no cabe duda que en el plano económico el gobierno procedió con un plan de largo plazo de cumplimiento de metas. En temas macroeconómicos -crecimiento, empleo, inflación- el gobierno de Sebastián Piñera terminó su tercer año con cifras positivas y muy cercanas a las metas que se había impuesto. En otros ámbitos, incluyendo la reforma tributaria, que incluyó la eliminación de algunos loopholes impositivos, el gobierno también avanzó hacia la modernización de la institucionalidad.

Si 2012 fue un año dominado por una discusión electoral, 2013 -año en que se realizarán elecciones parlamentarias y presidenciales- será aún más. Es de suponer que el patrón visto en 2012 seguirá. Las demandas sociales no se apaciguarán, la economía seguirá creciendo según la fuerte demanda interna y por el cobre en el exterior, y el gobierno avanzará en una modesta pero exitosa agenda de modernización institucional. La gran incógnita es si este escenario permitirá un repunte en la popularidad del presidente Piñera, si será posible transferir los méritos del gobierno al eventual candidato del oficialismo, o si al final el primer gobierno de derecha elegido desde 1958 terminará siendo un gobierno paréntesis. 


\section{REFERENCIAS}

CLACSO. 2012a. Cronología del Conflicto Social Chile, febrero 2012. Observatorio Social de las Américas, CLACSO.

CLACSO. 2012b. Cronología del Conflicto Social Chile, marzo 2012. Observatorio Social de las Américas, CLACSO.

Landerretche Gacitúa, Oscar. 2011. “La evolución del empleo en Chile 1990-2010: Un recálculo”. Revista Política 49 (2): 33-56.

La Tercera. http://www.latercera.cl

Observatorio Político-Electoral, UDP. 2012. Los ricos también votan. Participación electoral según nivel socioeconómico de las comunas en la Región Metropolitana. UDP. Santiago. http://www.icso.cl/wpcontent/uploads/2012/11/Informe-Abstenci\%C3\%B3n.pdf

Piñera, Sebastián. 2009. Programa de Gobierno para el Cambio, el Futuro y la Esperanza 2010 2014. Santiago: Coalición por el Cambio.

Piñera, Sebastián. 2010. "Del Chile del bicentenario al país de las oportunidades". Mensaje a la Nación de S.E. el Presidente de la República. Valparaíso.

Robert Funk es B.A. de la Universidad de Toronto, MSc. y PhD. de la London School of Economics. Subdirector del Instituto de Asuntos Públicos de la Universidad de Chile y profesor de Ciencias Políticas de la misma universidad.

E-Mail: rofunk@iap.uchile.cl 
